Archives de sciences sociales des religions

149 | janvier-mars 2010

Varia

\title{
Tradition orthodoxe et symboles religieux en
} Grèce

La loi sur le patrimoine ecclésiastique

Isabelle Dépret

\section{CpenEdition}

\section{Journals}

Édition électronique

URL : http://journals.openedition.org/assr/21890

DOI : $10.4000 /$ assr. 21890

ISSN : 1777-5825

Éditeur

Éditions de l'EHESS

Édition imprimée

Date de publication : 31 mars 2010

Pagination : 129-150

ISBN : 978-2-7132-2253-5

ISSN : 0335-5985

\section{Référence électronique}

Isabelle Dépret, «Tradition orthodoxe et symboles religieux en Grèce », Archives de sciences sociales des religions [En ligne], 149 | janvier-mars 2010, mis en ligne le 01 mars 2013, consulté le 19 avril 2019. URL : http://journals.openedition.org/assr/21890; DOI : 10.4000/assr.21890 


\section{Isabelle Dépret}

\section{Tradition orthodoxe et symboles religieux en Grèce La loi sur le patrimoine ecclésiastique}

\section{Introduction}

«Que (...) comme les représentations de la Croix (...), les saintes et vénérables icônes soient à nouveau élevées (...), aussi bien l'image de notre Seigneur Dieu et sauveur Jésus-Christ que celle de notre Dame immaculée, la sainte Théotokos, que celle des honorables anges et celle de tous les saints (...) ; qu'il soit prescrit d'embrasser les icônes et de se prosterner avec respect devant elles; de leur apporter de l'encens et des lumières, selon la pieuse coutume des anciens (...) Car l'honneur rendu à l'image atteint le modèle original et celui qui se prosterne devant l'image se prosterne devant la substance de celui qui est inscrit dans cette image. Ainsi, est affermi l'enseignement de nos saints pères, c'est-à-dire la tradition de l'Église universelle " ${ }^{1}$.

Cet extrait de l'horos ${ }^{2}$ du Concile de Nicée II nous renvoie directement à l'Empire romain oriental ainsi qu'aux processus de construction du christianisme orthodoxe. Ce concile, reconnu par l'Église en tant que VII ${ }^{\mathrm{e}}$ Concile œcuménique, clôt la première période iconoclaste, en réintégrant le culte des images saintes dans le dogme de la foi «correcte ». Ces clauses, qui remontent à l'an 787 de notre ère, restent valides au point que les icônes apparaissent aujourd'hui comme un trait fondamental de l'orthodoxie, tant du point de vue de l'art que des formes de piété ${ }^{3}$. La "tradition » peut être entendue comme un ensemble de représentations, valeurs, connaissances, attitudes et pratiques acceptées, au nom d'une continuité jugée nécessaire, entre passé et présent (Hervieu-Léger, 1999 : 539-540). De ce point de vue, l'Église orthodoxe de Grèce se présente, sans conteste, comme une institution traditionaliste. Les publications du Diaconat apostolique de cette Église affirment la responsabilité, pour celle-ci, de « conserver et transmettre indivis, inaltérés la foi apostolique et l'héritage reçu de nos

1. Concile de Nicée II, traduction du texte de l'horos dans Jean-Paul Migne, Encyclopédie théologique, Paris, 1847, vol. 13-1 ; Marie-France Auzépy, Les iconoclastes, Paris, PUF, 2006, p. 123 ; Gilbert Dagron, chap. 2, in Dagron G., Vauchez A., Parisse M., (dirs.), Histoire du christianisme, t. 4, Paris, Desclée de Brouwer, 1993, pp. 93-116.

2. L’horos ou définition dogmatique résume la pensée de la majorité des pères présents au Concile ainsi que l'argumentation avancée.

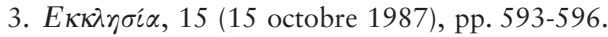


pères »(Metallinos, 1981) ${ }^{4}$. La notion de tradition s'impose ici comme norme pour l'institution et pour les fidèles.

Cet article, qui a pour contexte la Grèce contemporaine, est l'occasion de revenir, par le biais d'une étude de cas, sur cette notion et sur la place des icônes dans l'orthodoxie. On montrera, ici, comment ces références, croyances et pratiques dévotionnelles - re-sémantisées et mobilisées - ont pu s'articuler dans un enjeu politique et économique. On s'appuiera, dans cette perspective, sur des documents de nature juridique; sur la presse orthodoxe, en particulier la revue officielle $E \kappa \kappa \lambda \eta \sigma i \alpha$ (Église) ; sur la presse généraliste hellénique ${ }^{5}$.

On s'arrêtera d'abord sur une configuration conflictuelle, pour mieux cerner comment le thème de la tradition vient porter, dans ce contexte, une stratégie de résistance. On soulignera ensuite le rôle de symboles religieux dans le développement et l'issue d'une crise politico-ecclésiastique ayant pour cadre la Grèce largement sécularisée de la fin du $\mathrm{XX}^{\mathrm{e}}$ siècle.

\section{Le PASOK et la question de la fortune ecclésiastique}

\section{Un dossier sensible}

Au début du XIX ${ }^{\mathrm{e}}$ siècle, les structures ecclésiastiques, les activités du clergé orthodoxe s'inscrivent dans un cadre territorial et conceptuel impérial. Ayant survécu en tant qu'institution à l'effondrement de souverains temporels successifs, l'Église chrétienne orientale possède alors un patrimoine foncier et immobilier considérable : terres attachées aux monastères et aux églises, édifices, boutiques, biens matériels (Balta, 1995 ; Odorico, 1996 ; Deguilhem, 2003). Ce patrimoine s'est constitué au fil des siècles grâce aux cessions des dirigeants séculiers et surtout aux dons des fidèles (Konidaris, 1979 : 31-221). La prise de contrôle du territoire, dont une partie appartient à des habitants non chrétiens, une partie aux communautés et à l'Église orthodoxes, a constitué l'un des aspects de la formation du territoire grec moderne. Ces enjeux territoriaux et agraires ont marqué le développement du pays dans ses aspects géostratégiques, économiques, sociaux, politiques (Svoronos, $1997: 40-77)^{6}$.

La construction de l'État s'est traduite par d'importants transferts de propriété. Après l'insurrection de 1821, toutes les terres publiques ottomanes sont

4. Voir aussi Panagiotis Botsis, Qu'est-ce que l'orthodoxie. Brève explication de l'essence de l'orthodoxie et des différences entre les Églises, Athènes, s.l.n.d., p. 4.

5. Dans le corps du texte, on privilégie une translittération des termes grecs en caractères latins afin de rendre plus confortable la lecture des non-hellénophones. En revanche, pour ce qui concerne les références en bas de page, je reprends, par souci d'exactitude, les titres originaux, en caractères grecs.

6. En 2009, le cadastre du territoire grec est toujours en cours de réalisation. 
proclamées nationales en vertu du droit de la guerre : le protocole de juin 1830 précise que les terres ottomanes annexées n'impliquent aucune contrainte d'indemnisation. En revanche, pour ce qui concerne les terres anciennement privées ou communautaires, la gestion s'est avérée plus complexe. Les services judiciaires et administratifs grecs ont été contraints d'en référer au droit ottoman. En 1881, la convention permettant la cession à la Grèce de la Thessalie et d'un district d'Épire garantit les propriétés privées et communautaires ottomanes "légales " ${ }^{7}$. À l'issue des guerres balkaniques, la loi 147 du $1^{\text {er }}$ février 1914 reconnaît, de même, les ordonnances ottomanes gérant les biens fonciers privés ou communautaires ${ }^{8}$.

Toutefois, ces énoncés juridiques rendent très imparfaitement compte des pratiques effectives dans ce domaine. S'y sont ajoutés d'autres dispositifs législatifs et politiques. Ainsi, dans les années 1880, les gouvernements grecs mettent en œuvre une première réforme agraire : celle-ci se traduit par la confiscation des grands et moyens domaines, spécialement dans la plaine de Thessalie. Or, une partie notable de ces grands domaines appartient à des musulmans. D'un strict point de vue juridique, une logique de préférence confessionnelle peut être repérée : les propriétés communautaires et individuelles musulmanes ont été peu protégées, quoique des arguments juridiques, politiques, sociaux, sécuritaires ou nationaux aient été ici mis en avant (Nakos, 1984). À cet égard, les premières décennies du $\mathrm{XX}^{\mathrm{e}}$ siècle sont décisives : conventions d'échanges démographiques avec la Bulgarie et la Turquie, lois d'expulsion de "traîtres » ou de criminels, confiscation des biens de non détenteurs de la nationalité grecque, départ massif des populations musulmanes et afflux de chrétiens sur le territoire étatique, réforme agraire des années vingt, ont participé d'un transfert majeur de propriété foncière.

Si les ramifications ecclésiastiques orthodoxes ont pu préserver ou restructurer une partie de leur patrimoine, des confiscations, avec ou sans dédommagements, des recompositions patrimoniales suggèrent des relations complexes entre le pouvoir séculier et l'Église établie. Au XIX siècle, la constitution d'une Église autocéphale s'est accompagnée d'une restructuration des instances ecclésiastiques dans une logique volontariste qui se veut "modernisatrice ». En 18331834, sur décision du gouvernement, le nombre de monastères est réduit de manière drastique : sur cinq cent soixante-cinq monastères masculins, quatre cent douze sont fermés ; sur dix-huit couvents féminins, quinze sont supprimés.

7. Ainsi, l'article 4 de ce texte stipule : «Le droit de propriété sur des fermes, des pâturages, des prairies, des pacages, des forêts et toute autre espèce de terrain et immeuble possédés par des particuliers ou des communautés sur la base de firmans, hodjets, tapus ou autres titres de la loi ottomane, dans les localités cédées au royaume de Grèce sera reconnu par le gouvernement hellénique ".

8. La loi $147 \mathrm{du} 1^{\mathrm{er}}$ février 1914 précise : «Dans les provinces directement sous domination ottomane, la législation de l'État grec est pleinement introduite dans les villes. Toutefois, les ordonnances ottomanes sur les terres concernant des droits acquis de nature privée, conservent dans l'État grec leur validité ». 
Parallèlement, une partie des terres agricoles, propriété des monastères désertés, est reprise par l'État, avec pour objectif une réforme agraire (Frazee, 1969: 125126 ; Konidaris, 1991 : 11-22). La fortune des monastères à l'abandon doit alors alimenter une caisse : les fonds rassemblés doivent, en effet, permettre de rémunérer le personnel ecclésiastique, de restaurer les églises et les principaux monastères conservés (ibid. : 13-14).

$\mathrm{Au} \mathrm{XX}$ siècle, la question de la fortune foncière monastique orthodoxe est, à plusieurs reprises, l'objet de négociations serrées entre les gouvernements et la haute hiérarchie : en 1952, spécialement, sous le gouvernement Plastiras, l'Église orthodoxe de Grèce accepte de céder six cent mille stremmata de pâturages et cent cinquante mille stremmata de terres cultivables. Elle reçoit en échange des compensations, notamment des terrains à bâtir de grande valeur en Attique 9 . Ces précédents s'inscrivent en toile de fond lorsque, au milieu des années quatrevingts, le gouvernement socialiste grec décide de se saisir, à nouveau, d'un dossier particulièrement délicat.

En octobre 1985, en effet, peu après les élections législatives, les ministères grecs de l'Éducation nationale, de l'Économie, de l'Agriculture, de l'Aménagement du Territoire déposent un texte concernant le patrimoine monastique. Ce document inaugure un cycle de pourparlers entre le gouvernement socialiste d'Andrea Papandreou et la haute hiérarchie orthodoxe de Grèce (Konidaris, $1991 ; 50)^{10}$.

En janvier 1987, déplorant l'absence de solution consensuelle, le ministre de l'Éducation nationale et des Cultes, Adonis Tritsis, transmet au Saint-Synode, puis au Parlement, un projet de loi élargi et, à certains égards, radicalisé, intitulé "règlement relatif à des questions de patrimoine ecclésiastique ${ }^{11}$.

Développée au Parlement, dans la presse ainsi que dans une série d'interventions télévisées, l'argumentation du ministère de l'Éducation nationale met en avant des préoccupations de justice sociale, de redistribution des richesses du

9. L'objectif du gouvernement est de redistribuer les surfaces récupérées à deux cent mille paysans pauvres. $E \kappa \kappa \lambda \eta \sigma i \alpha, 3$ (1 ${ }^{\text {er }}$ février 1952), p. 44 ; 4-7 (15 février-15 mars 1952), pp. 8592 ; 18-19 (1 ${ }^{\text {er }}$ octobre 1952), pp. 272-274. Pour le début des années vingt, voir Theophilos

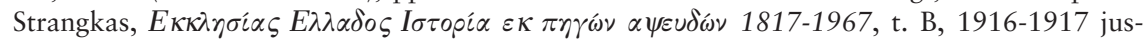
qu'en 1967, Athènes, 1970, pp. 1170, 1310, 1321, 1378.

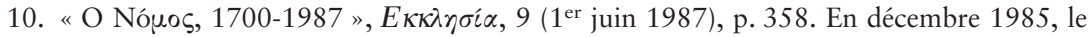
Synode transmet au ministère un mémorandum, qui, selon le juriste Iannis Konidaris, exprime des revendications " maximalistes ». Saint-Synode de l'Église de Grèce, $A \pi \delta$ ó $\varepsilon \iota \rho \alpha \alpha \iota \chi \mu \alpha \lambda \omega \sigma \iota \alpha \varsigma$, op. cit., 1987, pp. 85-88. Le ministre de l'Éducation nationale et des Cultes répond à l'Église huit mois plus tard, le 29 août 1986.

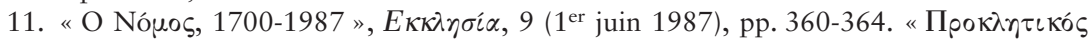

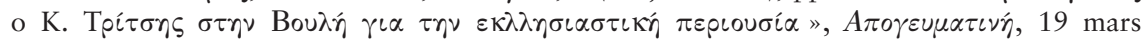
1987 , p. 4. Le projet A. Kaklamanis de 1985, centré sur le seul " patrimoine monastique ", était d'ambition plus restreinte. Le texte de 1987 inclut, en outre, une réforme des organes d'administration patrimoniale et des procédures de justice ecclésiastique. 
pays ; le souhait d'une meilleure mise en valeur du territoire ; enfin, un souci de transparence accrue des affaires de l'Église. Au-delà des aspects fonciers, un idéal de libéralisation, de démocratisation, de laïcisation semble inspirer ce texte.

L'exposé introduisant le projet souligne la prise en charge par l'État de quasiment tous les frais de fonctionnement de l'Église orthodoxe et rappelle que cette dernière n'a toujours pas honoré l'obligation, spécifiée par un décret de 1952 , de céder les $4 / 5^{\mathrm{e}}$ du patrimoine foncier monastique ${ }^{12}$. Selon ce rapport,

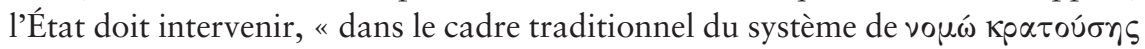

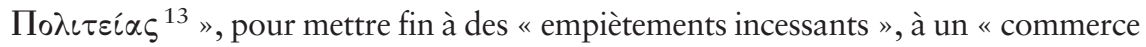
illégal » désavantageux, bref à la " corruption » d'un patrimoine largement inexploité. Cette richesse, en constante réduction, devrait être rendue à l'économie nationale et mise en valeur, "spécialement par des agriculteurs et des éleveurs démunis ${ }^{14}$.

\section{Une loi controversée}

Concrètement, le projet stipule qu'au terme de six mois à compter de la promulgation de la loi, les biens fonciers ruraux monastiques seront considérés comme propriété de l'État, à moins que le monastère ne prouve son statut de propriétaire $^{15}$. Or, pour nombre de terres, l'acte est inexistant, perdu ou détruit ${ }^{16}$.

L'État ou l'Office de Gestion du Patrimoine Monastique (ODEP) - l'organisme censé récupérer ces terres ${ }^{17}$ - pourront en céder l'usufruit à des agriculteurs, de préférence membres de coopératives, ou à des coopératives agricoles ${ }^{18}$. Une partie des revenus de cette exploitation devra être affectée à l'éducation nationale ${ }^{19}$.

En échange, les monastères doivent recevoir un pourcentage du produit brut de l'exploitation de leurs anciennes propriétés ${ }^{20}$. Ils conservent une portion de celles-ci, les surfaces jugées nécessaires à l'autosubsistance des moines ainsi qu'à

12. Il s'agit du décret no $2185 / 1952$.

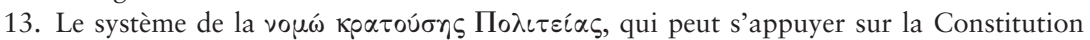
hellénique de juin 1975, donne la possibilité au législateur public d'intervenir dans certaines affaires de l'Église, à l'exclusion des questions strictement religieuses et dogmatiques.

14. Exposé introductif du ministère de l'Éducation nationale au projet de loi «Pú $\theta \mu \iota \sigma \eta$

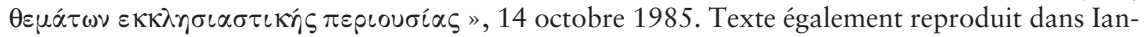
nis Konidaris, O Nóuos 700-1987..., 1987, annexe II, pp. 233-237.

15. En produisant un titre légal dûment enregistré, une disposition législative ou une décision judiciaire à l'encontre de l'État. Loi 1700-1987, article 3.

16. Ceci d'autant que le Code civil n'impose l'enregistrement des legs et successions que depuis 1946.

17. Loi 1700-1987, article 1.

18. Idem, article 2 .

19. Idem, article 9.

20. Idem, article 2 . 
la protection de l'environnement ${ }^{21}$. Le projet envisage la rétrocession de terres à des monastères ne disposant pas d'un patrimoine suffisant ${ }^{22}$. Un soutien budgétaire annuel à l'œuvre de l'Église orthodoxe est par ailleurs prévu ${ }^{23}$.

Les biens immobiliers considérés dans ce texte sont essentiellement ruraux : terrains agricoles ou susceptibles d'exploitation agricole, forêts ou zones forestières ; pâturages, prairies ; enfin terrains à bâtir, y compris des terrains classés urbains en 1987, s'ils n'ont été inscrits dans le plan de ville qu'après 1952, c'està-dire, assez récemment ${ }^{24}$.

Plus hardi encore, l'article 8 du texte modifie la composition des organes d'administration des biens ecclésiastiques. Jusqu'alors présidé par l'Archevêque d'Athènes, le Conseil d'Administration de l'ODEP est désormais composé de membres, dont le Président, en majorité nommés par le ministère de l'Éducation nationale ${ }^{25}$. Est également prévue l'entrée de membres élus, clercs et laïcs, dans les conseils métropolitains et paroissiaux, ainsi que d'avocats de la défense dans les tribunaux ecclésiastiques ${ }^{26}$.

Les dispositions de ce projet concernent exclusivement les églises et monastères de l'Église orthodoxe de Grèce et de Crète : les monastères du Patriarcat de Constantinople en Grèce, ceux dépendants d'autres Patriarcats orthodoxes échappent à ces mesures ${ }^{27}$. À la fin du XX siècle, la Grèce compte environ deux mille cinq cents moines et moniales orthodoxes, Mont Athos exclu. Les prêtres de l'Église orthodoxe sont, quant à eux, environ huit mille cinq cents.

En l'absence d'enregistrement systématique, l'ampleur du patrimoine de l'Église orthodoxe en Grèce reste largement inconnu, y compris, officiellement, par la haute hiérarchie. Selon une estimation du ministère de l'Agriculture, à la fin du XX $\mathrm{X}^{\mathrm{e}}$ siècle, le patrimoine ecclésiastique orthodoxe rural, propriétés urbaines exclues, se monterait à un million trois cent mille stremmata, soit cent trente mille hectares (Tsouma, Tassoulia, 1986) ${ }^{28}$.

21. Idem, articles 2 et 4.

22. Idem, article 3.

23. Idem, article 10 .

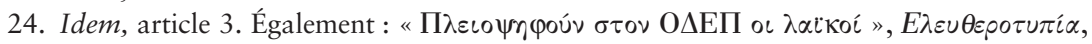
13 mars 1987, p. 16.

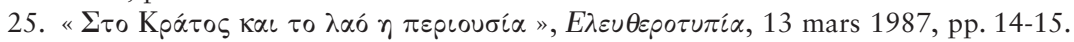

26. Idem, articles 8 et 11 .

27. Loi 1700-1987.

28. 1300000 stremmata, dont 376000 stremmata de zones forestières, 735000 stremmata de pâturages, 190000 stremmata de terres agricoles, le montant des biens d'anciens vakifs étant mal connu. 


\section{Tradition et stratégie de résistance}

Le terme de tradition ( $\pi \alpha \rho \alpha ́ \delta \circ \sigma \eta)$ apparaît avec une considérable récurrence dans la presse orthodoxe de Grèce ${ }^{29}$. On retrouve, notamment, cette notion dans le compte rendu proposé par la revue $E \kappa \kappa \lambda \eta \sigma i \alpha$, de la célébration du "dimanche de l'orthodoxie ", en mars $1987^{30}$. Cette journée commémore le rétablissement des saintes icônes, le 11 mars 843, à Constantinople (Lemerle, 1975 : 79-84 ; Kaplan, 2007 : 180). En 1987, l’Église fête le $1200^{\text {e }}$ anniversaire du Concile de Nicée II, ce qui explique, tout d'abord, l'abondance des références sur ce thème ${ }^{31}$. Toutefois, les enjeux d'actualité leur confèrent un sens tout particulier.

Dès 1986, la haute hiérarchie orthodoxe de Grèce est en ordre de combat. Le 18 mars 1987, les évêques convoqués en session extraordinaire décident d'intensifier la «lutte » contre le projet de loi Tritsis ${ }^{32}$. Mobilisation du clergé, du peuple, des milieux politiques ; communication tous azimuts ; appels adressés aux autres Églises orthodoxes, au Vatican, à des organisations internationales participent d'une stratégie de résistance aux multiples facettes ${ }^{33}$. Au cours des dernières décennies du XXe siècle, l'Église orthodoxe de Grèce continue d'entretenir avec le Vatican des rapports de forte méfiance ${ }^{34}$. Toutefois, sur certains axes,

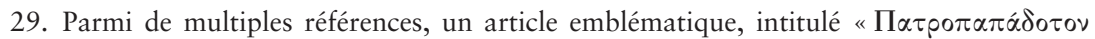
$\sigma \varepsilon \hat{\beta} \alpha \sigma$ " [Le respect de la tradition], discours prononcé dans la cathédrale d'Athènes pour la fête de la "victoire de l'orthodoxie ", le premier dimanche de Carême, le 28 février

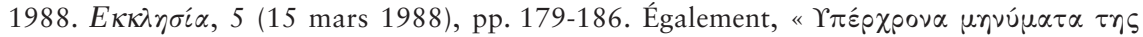

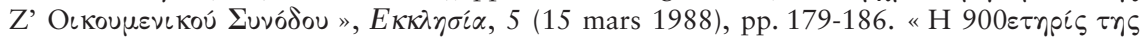

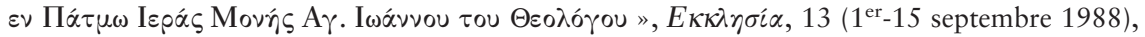
spécialement p. 467.

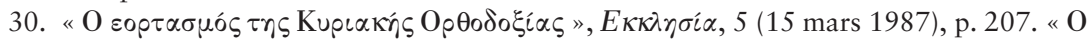

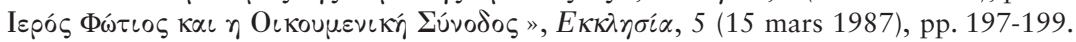

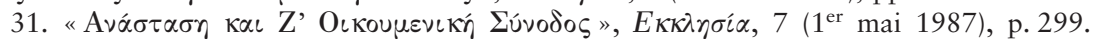

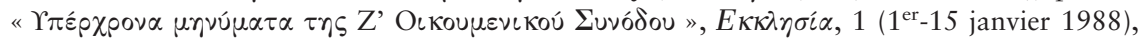
pp. 6-9; 7 (1 ${ }^{\text {er }}$ mai 1988$)$, pp. 257-258; 8 (15 mai 1988), pp. 305-307; 9 (1 ${ }^{\text {er }}$ juin 1988),

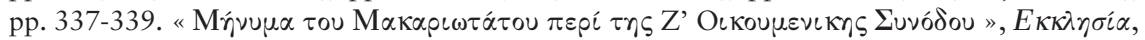
11 ( $1^{\mathrm{er}}-15$ juillet 1987), pp. 456-457; 14 (1 ${ }^{\mathrm{er}}$ octobre 1987), pp. 561-563; 15 (15 octobre 1987), pp. 593-596; 16 (1 er $^{\text {er }}$ novembre 1987), pp. 625-628.

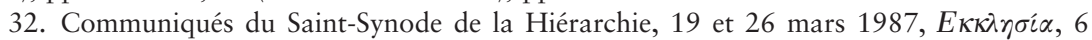
(1 ${ }^{\text {er }}-15$ avril 1987), pp. 237-238 et p. 239.

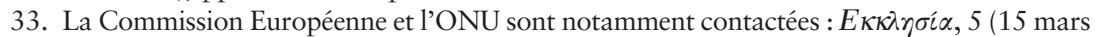

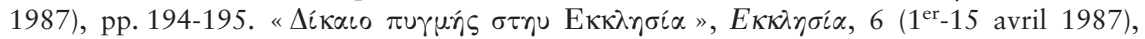

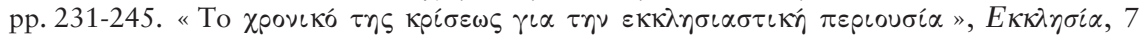

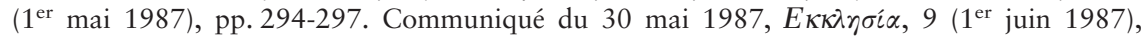

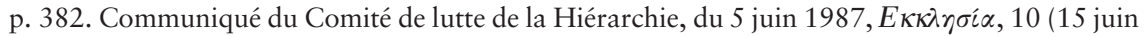

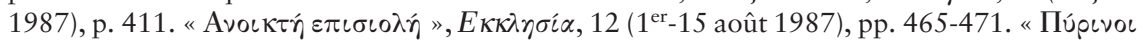

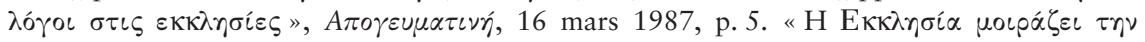

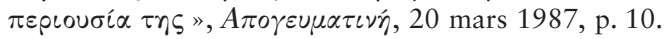

34. Conforme sur le fond à bien d'autres articles de la presse grecque au cours de ces années, un texte du métropolite de Dimitrias, Christodoulos, publié dans le journal To Bŕnu , le 25 août 1991, est intitulé « Le mouvement vers l'unité est torpillé ». L'article dénonce l'activisme "scandaleux » des communautés uniates dans les pays de l'Est sortis affaiblis du communisme. 
l'Église catholique romaine est reconnue comme une autorité de poids et comme possible alliée ${ }^{35}$.

L'Encyclique pastorale du 20 mars 1987 met en relief l'argumentation de la haute hiérarchie orthodoxe dans ce litige. Selon ce document, l'Église est bien disposée à céder une grande partie de ses terres rurales à des agriculteurs pauvres, mais non, comme le prévoit le texte, à des coopératives, qui seraient minées par les déchirements partisans :

"Sous prétexte de régler la question du patrimoine ecclésiastique, le gouvernement (...) s'ingère de manière inacceptable dans les affaires internes de l'Église (...) il ouvre la voie à une division du peuple (...) et à la corruption interne de (l'Église) par l'entrée de fonctionnaires nommés selon une logique partisane ${ }^{36}$.

Dans un ouvrage intitulé, de manière significative, Tentative de capture de l'Église, le Saint-Synode insiste :

«Nous ne combattons pas pour des champs et des propriétés mais pour la liberté et l'indépendance de l'Église » ${ }^{37}$.

La presse ecclésiastique, invoquant le droit canon, souligne abondamment le rôle primordial de l'évêque en tant qu'administrateur des affaires de l'Église ${ }^{38}$. Est également cité le $12^{\mathrm{e}}$ canon du Concile de Nicée II - nous retrouvons ce concile... - qui interdit aux évêques et aux abbés de donner ou de vendre aux fonctionnaires du pouvoir temporel des biens ecclésiastiques ${ }^{39}$. La fidélité soulignée à la tradition vient s'inscrire ici dans ce contexte défensif ${ }^{40}$.

Pour le Saint-Synode, le gouvernement aurait rompu le régime de la synallilia, que constituerait le "régime actuel » des rapports entre l'Église et l'État en Grèce ${ }^{41}$. Cette notion - parfois traduite par " harmonie » ou " réciprocité »-

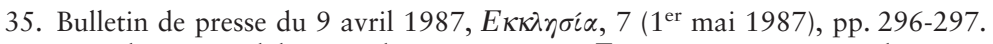

36. Encyclique synodale 2446 du 20 mars $1987, E \kappa \kappa \lambda \eta \sigma i \alpha, 6$ (1 $1^{\mathrm{er}}-15$ avril 1987), pp. 224-

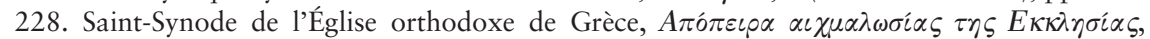

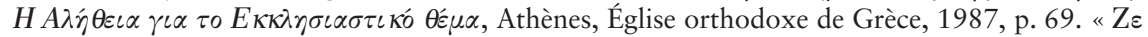

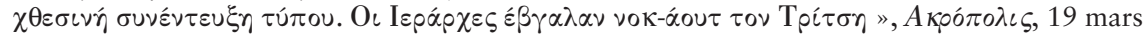
1987 , p. 5.

37. Idem, p. 6, pp. 66-67.

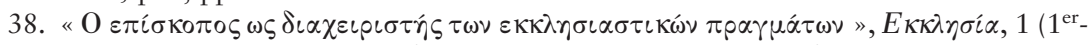

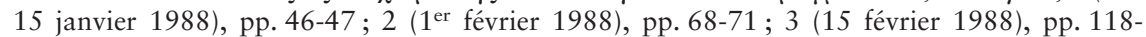

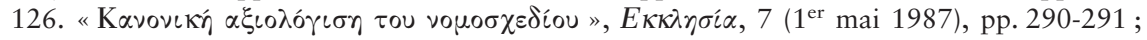
17 (15 novembre 1987), pp. 661-663.

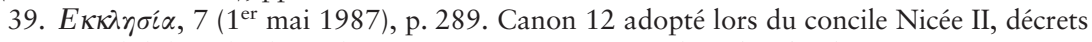
repris par Adolphe Charles Peltier, in J.-P. Migne, Encyclopédie théologique, Paris, 1847, vol. 13-14.

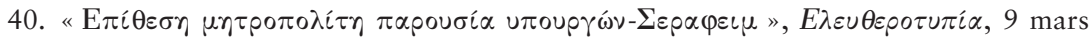
1987, p. 12. Ce journal évoque les attaques prononcées en chaire contre le gouvernement, le 8 mars 1987, par le métropolite de Peristeri, Chrysostomos, lors de la liturgie célébrée le jour

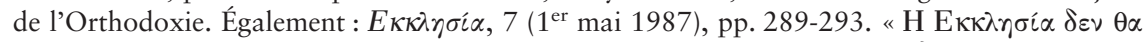

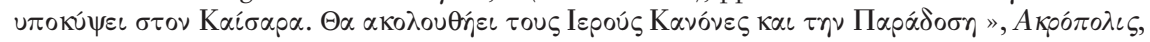
26 avril 1987, p. 5.

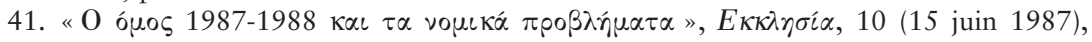
pp. 406-409. 
renvoie directement à l'idéologie politique de l'Empire byzantin ${ }^{42}$. Une déclaration de l'empereur Jean Tsimiskis, qui règne de 969 à 976, illustre ce modèle idéal-typique: "Je connais deux pouvoirs sur cette terre et dans cette vie, l'empire et le sacerdoce. Au premier, le Créateur a confié le soin des âmes, au second le soin des corps. Les deux parties ne souffrent-elles d'aucun dommage, l'ordre règne sur le monde » (Ahrweiler, 1975 : 129-147). Conçue, reprise par des intellectuels, des hommes d'Église ou des Empereurs, la synallilia désigne ces rapports de coopération étroite entre l'Église et le souverain temporel, deux piliers de l'État aux compétences distinctes (Hussey, 1986 : 299-301 ; Geanakoplos, 1965 ; Dagron, 1996). En 1987-1988, c'est avant tout à ce modèle que se réfère la hiérarchie orthodoxe de Grèce.

Dans un climat houleux, ce projet controversé est adopté, le 8 avril 1987, par les députés du PASOK - le parti au pouvoir - et du parti communiste ${ }^{43}$. L'opposition conservatrice néo-démocrate refuse, pour sa part, de cautionner un texte "fallacieux, anti-ecclésiastique, anticonstitutionnel et dangereux d'un point de vue national » ${ }^{44}$. Toutefois, le récit ne s'achève pas ici.

\section{Symboles religieux et mobilisation : une médiation efficace ?}

\section{La pluralité des registres}

En 1987 et 1988, la haute hiérarchie a souhaité mobiliser l'ensemble des rangs de l'Église - évêques, prêtres de paroisse, moines, laïcs - et souligner l'union entre clergé et peuple dans une lutte qui se veut sacrée ${ }^{45}$. Dans une

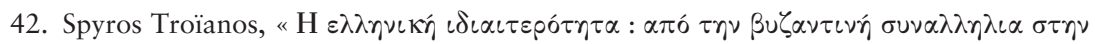
$\varepsilon \pi \iota \kappa \rho \alpha \tau о \cup ์ \sigma \alpha \theta p \eta \sigma \kappa \varepsilon i \alpha$ », intervention à l'Académie des études théologiques, Athènes, $1^{\text {er }}$ avril 2006.

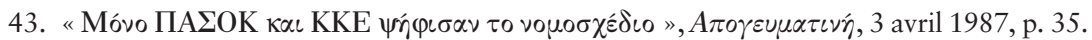

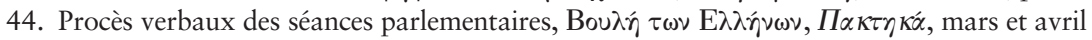

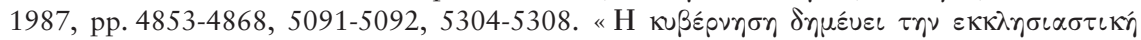

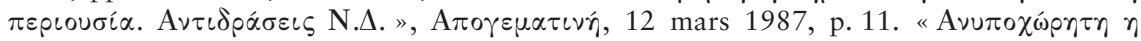

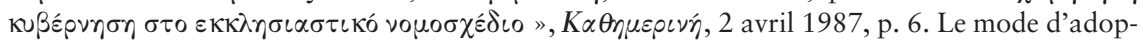
tion du projet - par la procédure d'urgence - fait également l'objet de vives critiques. Le texte est promulgué le 6 mai 1987 sous le numéro n 1700-1987.

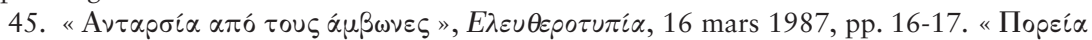

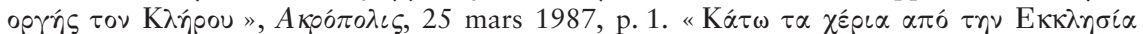

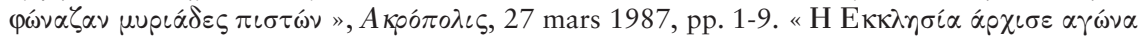

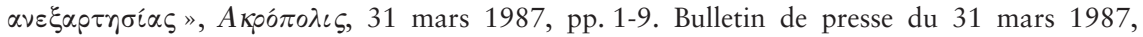

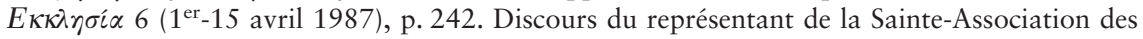

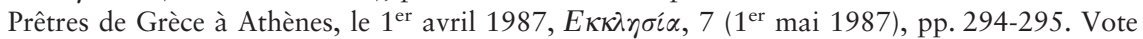

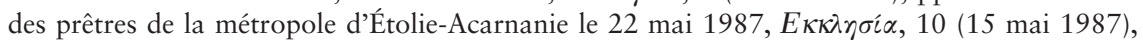

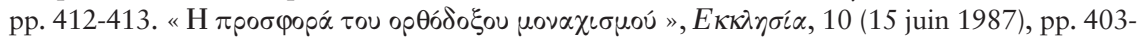

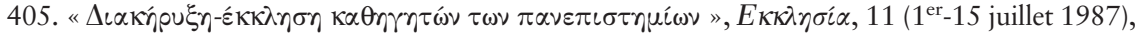

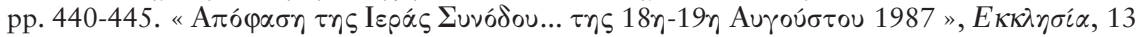
(1 ${ }^{\mathrm{er}}-15$ septembre 1987), pp. 513-515. "To $\Sigma u \lambda \lambda \alpha \lambda \eta \tau$ in 
allocution virulente prononcée devant des centaines de milliers de manifestants, le 5 avril 1987, Théodoros Zissis, professeur à la Faculté de Théologie de Thessalonique insiste sur ces deux aspects ${ }^{46}$. Le 25 mars, les évêques orthodoxes boycottent ostensiblement les cérémonies politiques et militaires associées à la fête nationale ${ }^{47}$. Le même jour - jour de la fête chrétienne de l'Annonciation - toutes les églises orthodoxes du pays carillonnent gravement en signe de deuil ${ }^{48}$. L’Église se proclame en situation de persécution. Plusieurs manifestations fleuve de soutien à l'Église se succèdent au printemps 1987 dans les plus grandes villes du pays ${ }^{49}$. Une contre-offensive juridique est également menée : durant l'été 1987, le Synode saisit le Conseil d'État et plusieurs monastères engagent une procédure devant la Cour Européenne des Droits de l'Homme ${ }^{50}$. Après la promulgation de la loi 1700-1987, le Saint-Synode fait savoir qu'il n'appliquera pas un texte anti-canonique ${ }^{51}$.

Dans ce climat polémique, des symboles religieux ont pu prendre place et se charger de significations particulières. Ceci vaut, notamment, pour l'aigle bicéphale, présent lors des grandes manifestations de $1987^{52}$. L'aigle noir à deux têtes sur fond d'or - symbole utilisé par le Patriarche de Constantinople et, aujourd'hui, par l'Église orthodoxe de Grèce - fut l'emblème de la dynastie des Paléologues, les derniers empereurs byzantins (Svoronos, 1914 : 1-67). Lors des

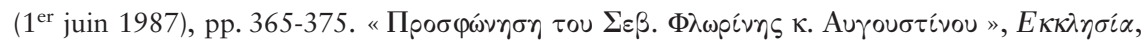

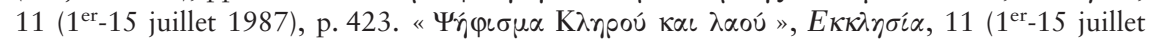

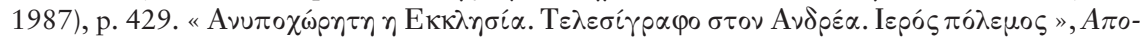

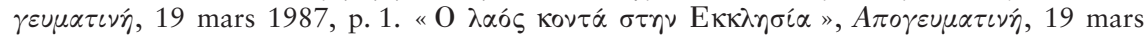

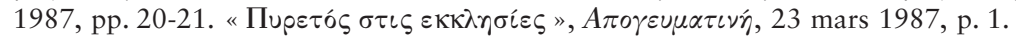

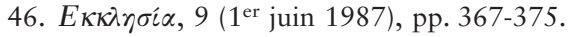

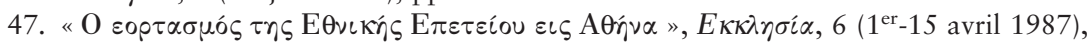
pp. 246-249.

48. AFP Athènes, 26 mars 1987.

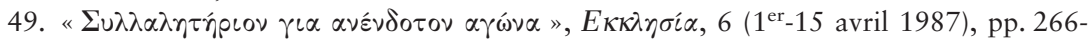

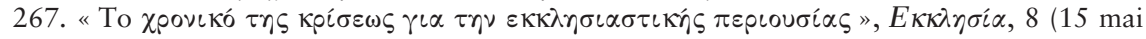

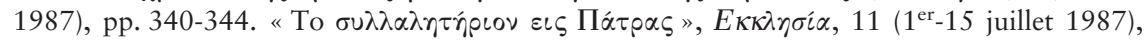
pp. 421-430. Dans un discours virulent, et très suivi, prononcé à l'église Saint-Panteleïmon d'Acharnon, en Attique, le métropolite de Florina, Augoutinos Kantiotis, exhorte les fidèles à

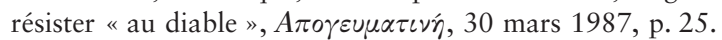

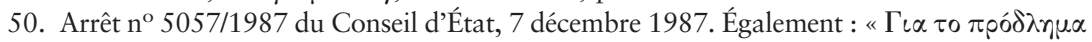

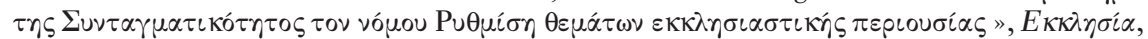

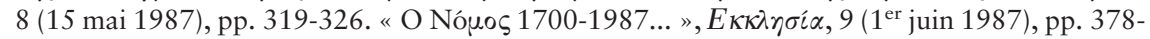

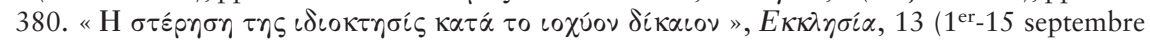
1987), pp. 546-549. Arrêt de la Cour Européenne des Droits de l'Homme, 21 novembre 1994 portant sur l'affaire no 10/1993/405/483-484 « Holy monasteries vs Greece ».

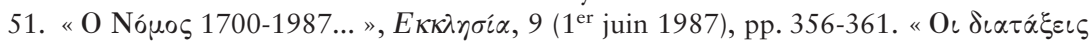

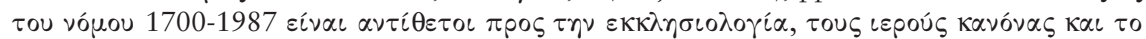

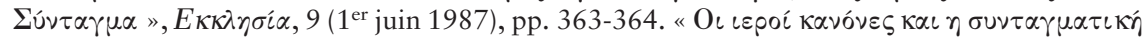

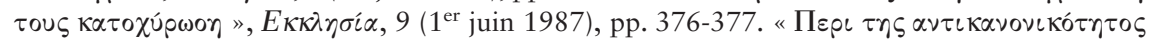

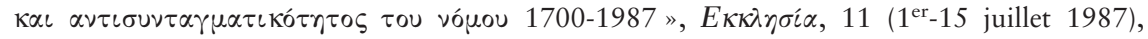

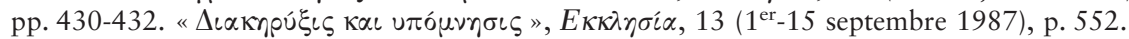

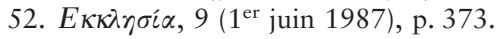


rassemblements de 1987, l'aigle bicéphale acquiert une dimension spécifique et se constitue en point de ralliement autour d'une Église qui se veut forte et unie ${ }^{53}$.

En 1987 et 1988, dans une série d'articles consacrés au Concile de Nicée II, le périodique $E \kappa \kappa \lambda \eta \sigma i \alpha$ en rappelle l'un des grands apports : affirmer un devoir de respect envers les icônes, lesquelles "véhiculent l'énergie divine (...) peuvent produire des miracles (...), constituent une tradition héritée de nos pères ${ }^{54}$. Ces clauses s'ancrent dans les pratiques et les manifestations qui accompagnent, en novembre 1987, la venue à Athènes de l'icône Axion Esti. Habituellement conservée au Mont Athos, cette icône de la Vierge à l'enfant est reçue au Pirée, le 4 novembre 1987, avec les plus grands honneurs ${ }^{55}$.

Transportée en procession, elle est ensuite exposée, dix-huit jours durant, dans la cathédrale orthodoxe d'Athènes ${ }^{56}$. La presse ecclésiastique réserve des pages entières à cette icône et au récit de ces dix-huit jours ${ }^{57}$. Des milliers de personnes de tous âges, bien portants ou malades, parfois accompagnées d'enfants en bas âge, parfois munies d'un bout de tissu, approchent cette représentation de la Vierge, afin que celle-ci leur apporte santé, guérison, force ${ }^{58}$. À l'issue de leur visite, les moines athonites se déclarent impressionnés par l'affluence ininterrompue des fidèles, prêts à attendre des heures et à supporter les intempéries pour venir prier à genoux devant cette icône réputée miraculeuse ${ }^{59}$ et l'embrasser.

\section{L'icône Axion Esti et le recul du gouvernement}

Pourtant, le transfert et l'exposition, en novembre 1987, de cette icône peuvent aussi être considérés à la lumière de cette crise politico-ecclésiastique. L'icône Axion Esti est, en effet, appelée à Athènes sur décision synodale - et à l'initiative du Patriarche de Constantinople - pour « soutenir le clergé et le peuple

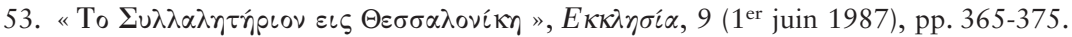

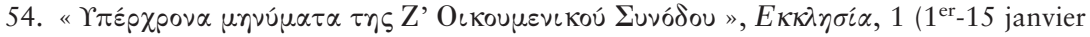
1988), p. 7.

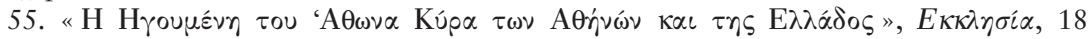
( $1^{\mathrm{er}}-15$ décembre 1987$)$, pp. 748-751; 4 (1 ${ }^{\mathrm{er}}$ mars 1988$)$, pp. 164-167.

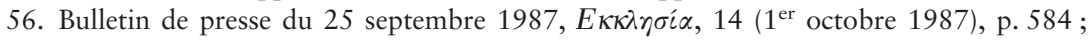
18 (1 ${ }^{\mathrm{er}}-15$ décembre 1987), pp. 748-741.

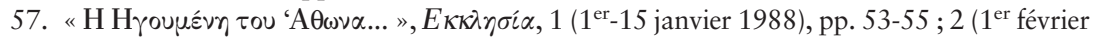
1988), pp. 82-84; 3 (1988), pp. 135-139; 4 (1 ${ }^{\text {er }}$ mars 1988), pp. 164-166 ; 5 (15 mars 1988),

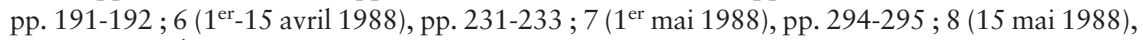

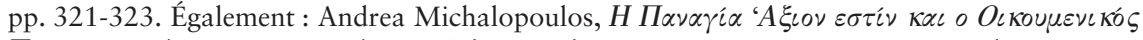
$\Pi \alpha \tau \rho \iota \alpha ́ \rho \chi \eta \varsigma \Delta \eta u \dot{n} \tau \rho \iota \varsigma \varsigma \sigma \tau \eta \nu A \theta \dot{\nu} \alpha$, Athènes, s.1., 1988. Je remercie Katerina Seraïdari, qui m'a indiqué cette référence émanant de l’Église orthodoxe.

58. AFP Athènes, 5 et 6 novembre 1987.

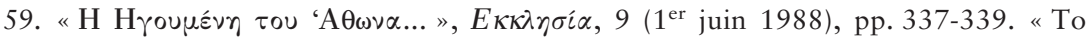

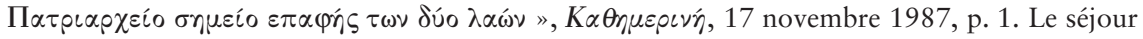
de l'icône Axion Esti à Athènes, prévu initialement jusqu'au 18 novembre, est prolongé jusqu'au 23 novembre, sur décision de la Sainte-Épistasie, "à la demande des fidèles ". 
durement éprouvés " ${ }^{60}$. La presse ecclésiastique rappelle, alors, que la Vierge Marie est aussi appelée "protectrice de la nation hellénique " ou "Général

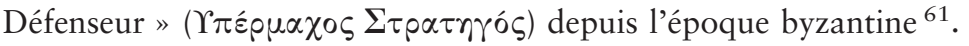

Il faut souligner qu'au printemps 1987, le Patriarche orthodoxe de Constantinople, alerté, apporte son soutien à l'Archevêque d'Athènes dans son opposition au projet Tritsis ${ }^{62}$. Ce texte de loi ne serait-il pas anti-canonique ${ }^{63}$ ? Cette prise de position encourage d'autres Églises orthodoxes à s'exprimer dans ce sens ${ }^{64}$. Au cours de cette période, l’Église de Grèce menace de renoncer à son statut d'Église autocéphale pour se replacer sous la juridiction directe de Constantinople ${ }^{65}$. Le Patriarche est attendu en Grèce du 13 au 18 novembre $1987^{66}$.

Ce contexte de forte pression éclaire un recul du gouvernement sur ce dossier. À partir de septembre 1987, la gestion de la "question ecclésiastique " semble directement reprise en mains par le Premier ministre et ses conseillers, courtcircuitant ainsi l'un des principaux ministres compétents : celui de l'Éducation Nationale et des Cultes. Plusieurs rencontres entre Andrea Papandreou et l'archevêque d'Athènes, Mgr Serapheim, inaugurent la reprise de négociations sur la base d'un texte largement remanié, tandis que la loi 1700-1987 est désactivée ${ }^{67}$.

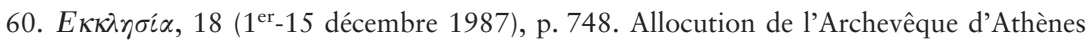

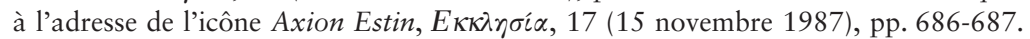

61. Cette qualification est utilisée notamment dans l'hymne Akathyste. "A 'A

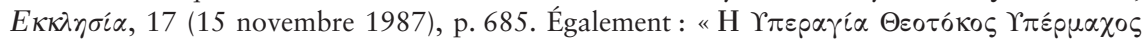

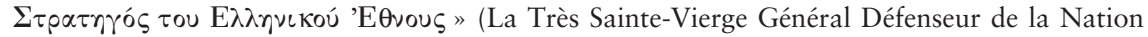

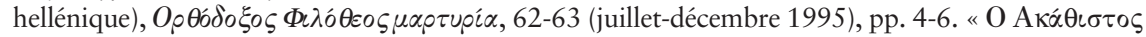

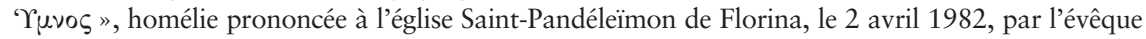
de Florina, Avgoustinos Kandiotis.

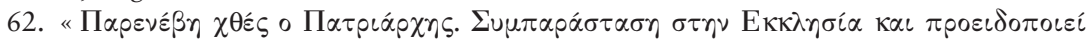

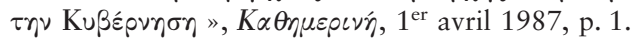

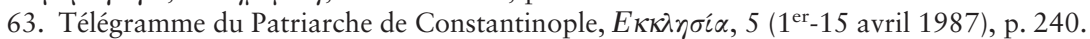

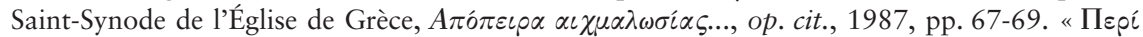

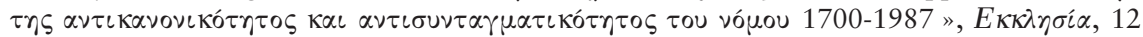

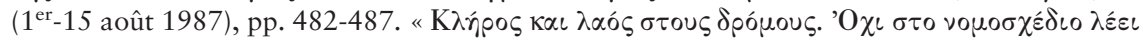

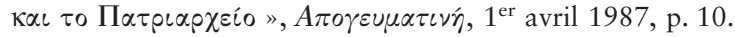

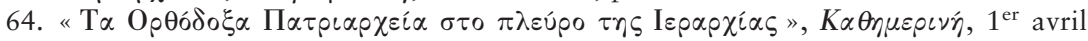
1987, p. 1.

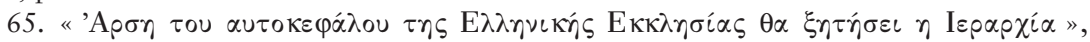

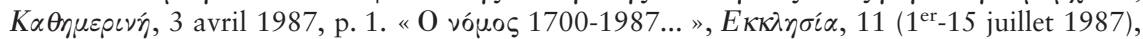

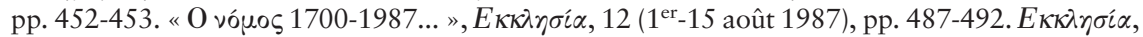

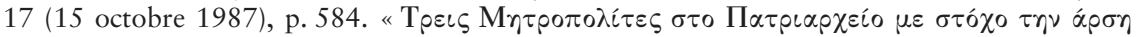

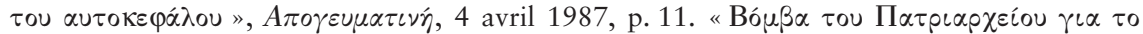

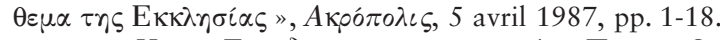

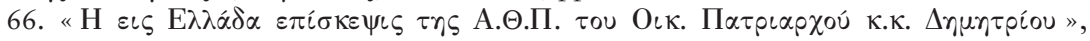

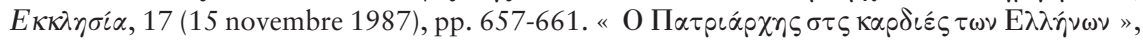

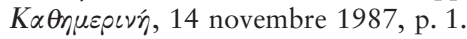

67. Communiqué de la haute hiérarchie du 18 septembre $1987, E \kappa \kappa \lambda \eta \sigma i \alpha, 14$ (1 $^{\text {er }}$ octobre

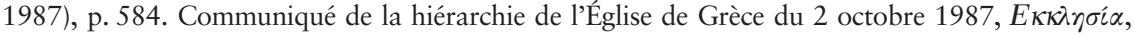
15 (15 octobre 1987), p. 619. Bulletin de presse du 30 décembre $1987, E \kappa \kappa \lambda \eta \sigma i ́ \alpha, 1$ (1 ${ }^{\mathrm{er}}-15$ janvier 1988), pp. 58-59. Rencontre entre le Premier ministre et l'Archevêque d'Athènes le 18 février 
En octobre 1987, dans un communiqué, le Saint-Synode se déclare satisfait de la tournure des choses ${ }^{68}$.

Après une confrontation dramatisée, la pacification des rapports entre l’Église et le pouvoir temporel coïncide avec le séjour simultané, à Athènes, de l'icône Axion Esti et du Patriarche de Constantinople. Il faut insister sur ce qui distingue l'évêque de Constantinople de l'image de la Vierge ${ }^{69}$ : d'un côté, un chef religieux exerçant une autorité, fut-elle formelle, sur plus de cent millions d'orthodoxes dans le monde; de l'autre, un objet matériel, dont la dimension sacrée est affirmée par le dogme chrétien orthodoxe et par la croyance des fidèles. Pourtant, en novembre 1987, les dirigeants ecclésiastiques, l’État grec, les pratiquants semblent étroitement articuler ces deux figures religieuses. D'une part, en effet, la personne physique du Patriarche semble sublimée par sa figure symbolique, incarnation de la fonction patriarcale dans sa continuité pluriséculaire; d'autre part, l'icône de la Vierge tend à être érigée en figure vivante, dotée d'une personnalité et de pouvoirs surnaturels.

Ces deux symboles religieux, venus soutenir l'Église orthodoxe de Grèce ${ }^{70}$, ne sont pas simplement investis d'un sens religieux. Ils présentent aussi un caractère politique. Le Patriarche est reçu par les plus hautes autorités grecques ${ }^{71}$. Cependant, l'icône Axion Esti est, elle aussi, accueillie avec les égards réservés à un chef d'État : elle est solennellement attendue non seulement par l'Église ${ }^{72}$, mais aussi par cinq ministres - parmi lesquels ceux de la Défense et de l'Éducation nationale - ainsi que par d'autres personnalités ${ }^{73}$. Aussi, ces deux "événements », dont le maire d'Athènes souligne la portée ${ }^{74}$ et qui auraient pu

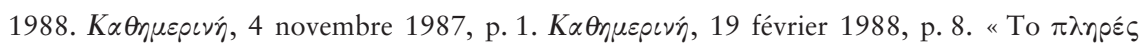

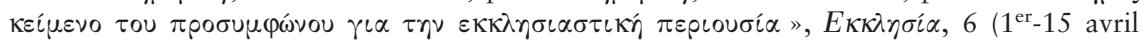
1988), pp. 211-214.

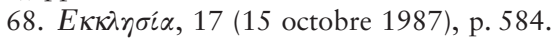

69. Voir, pour une approche interne et une mise en relief du rôle du Patriarcat, les deux

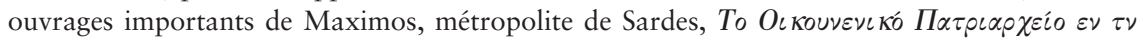

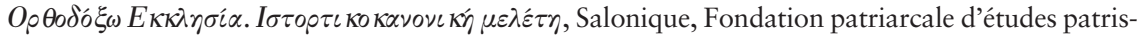
tiques, 1972. Grigorios Papathomas, archimandrite, Le Patriarcat cecuménique de Constantinople y compris la Politeia monastique du Mont Athos dans l'Europe unie. Approche nomocanonique, Katerini, Ekektasi, 1998.

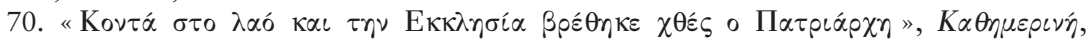
16 novembre 1987, p. 1. "H $\varepsilon \iota \varsigma$ E $\lambda \lambda \alpha \dot{\alpha} \delta \alpha \varepsilon \pi i \sigma \kappa \varepsilon \psi \iota \varsigma . .$. ", voir n. 70.

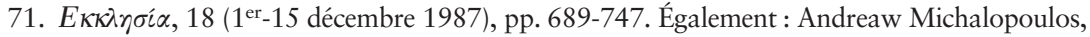

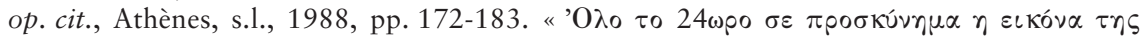

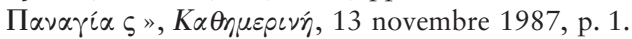

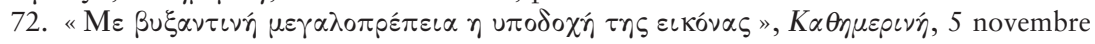
1987, p. 1.

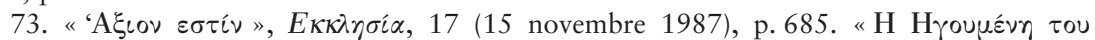
'A $\theta \omega \nu \alpha \ldots$ " $, E \kappa \kappa \lambda \eta \sigma^{\prime} \alpha, 2$ (1 ${ }^{\text {er }}$ février 1988), pp. 82-86 ; 3 (15 février 1988), pp. 138-140 ;

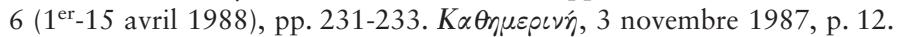

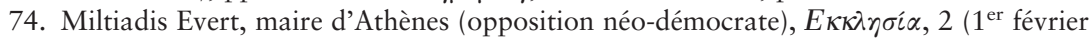
1988), pp. 87-88. 
constituer des pressions supplémentaires sur le gouvernement, viennent-ils, in extremis, consacrer la paix et la coopération restaurées entre deux instances de pouvoir ${ }^{75}$. On peut parler, en ce sens, d'une manifestation apotropaïque et purificatrice, organisée par l'Église, avec la participation de l'État.

\section{Conjurer de possibles tensions au sein de l'Église}

La convention du 11 mai 1988, signée par des représentants du gouvernement et du Synode abroge, pour cent quatre-vingt-seize monastères, les dispositions de la loi Tritsis ${ }^{76}$. Quelques jours plus tôt, le ministre de l'Éducation nationale, estimant avoir échoué sur ce dossier, avait présenté sa démission ${ }^{77}$. La loi 17001987, théoriquement en vigueur en 2008, n’a jamais été appliquée. L’Église a-t-elle remporté une victoire dans ce bras de fer?

Cette institution religieuse ne constituant pas un bloc monolithe, on peut se demander dans quelle mesure le conflit le plus visible - entre Église et État - n'a pas refoulé à l'arrière-plan d'autres nœuds de friction, cette fois au sein même de l'Église. La désactivation des lois $1700-1987$ et $1800-1988^{78}$ a préservé un équilibre entre plusieurs segments et, peut-être, neutralisé des tensions potentielles. Il faut d'abord penser aux tensions entre plusieurs interprétations du message orthodoxe. En effet, le gouvernement socialiste, lui aussi, se réfère dans les années quatre-vingts aux principes «authentiques»du christianisme ${ }^{79}$. Le texte de la loi 1700-1987, les déclarations du chef du gouvernement, celles du ministre de l'Éducation nationale durant la période étudiée, expriment un profond respect pour la religion orthodoxe ${ }^{80}$. Certes, selon plusieurs prélats, ce discours serait purement «hypocrite». Pourtant, les discours et certains actes

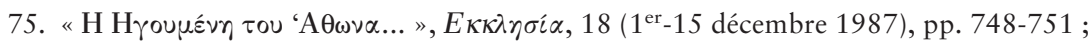
7 (1 ${ }^{\mathrm{er}}$ mai 1988$)$, pp. 294-295. Le Premier ministre, le 18 novembre 1987 , évoque au cours de son discours la "récente crise entre l'Église et l'État ", devant une délégation athonite qui

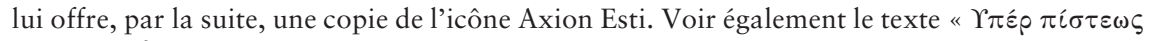

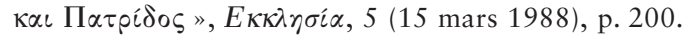

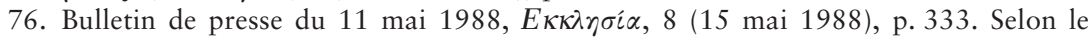
Synode de l'Église de Grèce, il y aurait trois cent soixante monastères orthodoxes en Grèce à la fin des années quatre-vingts. Voir le texte de la loi 1811-1988, du 6 octobre 1988.

77. A. Tritsis présente sa démission le 4 mai 1988, démission acceptée par le Premier

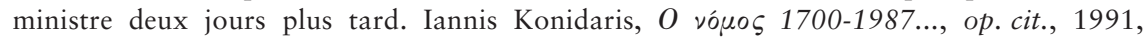
pp. 203-204.

78. Loi 1811-1988 du 6 octobre 1988.

79. Illustratives, à cet égard, sont les instructions officielles attachées à la loi de l'enseignement primaire et secondaire de 1985, selon lesquelles les élèves du pays doivent sauve-

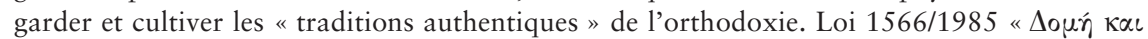

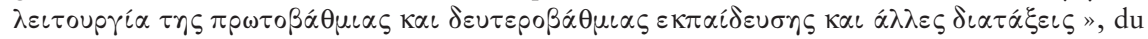
30 septembre 1985. Comptes-rendus des débats télévisés des 20 et 23 mars 1987 concernant

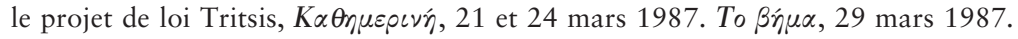

80. Les articles de la loi 1700-1987 désignent, de manière respectueuse, les "saintes églises ", les "saints monastères ". Voir les articles 3, 6, 10 de la loi 1700-1987. 
émanant des plus hautes autorités politiques témoignent des relations privilégiées entre l'État et l'orthodoxie en Grèce. L'État grec ne s'est jamais posé comme laïque. Depuis la création de la Grèce en 1830, l'Église orthodoxe bénéficie d'une position «dominante ", statut consolidé juridiquement (Frazee, 1969 ; Manitakis, 2000 ; Papastathis, 1999 ; Sotirelis, 1993 ; Dépret, à paraître ; Anastassiadis, 2007). On pense aussi aux articulations entre la logique collégiale - appliquée en 1987-1988 - et la place prééminente de l'archevêque d'Athènes, qui joue un rôle-clé dans le dénouement de la crise ${ }^{81}$. Il s'agit également des solidarités et frictions entre clercs et laïcs ${ }^{82}$; entre haut et bas clergé ; entre prêtres - salariés de l'État - et moines.

Dès la fin de l'année 1986, une série de personnalités ou d'instances religieuses se saisissent du dossier : il s'agit d'abord du Synode plénier de la haute hiérarchie - instance rassemblant l'ensemble des évêques de l'Église de Grèce. Cette instance, qui ne se réunit, normalement qu'une fois l'an, est convoquée en plusieurs sessions extraordinaires, de 1986 à 1988, qui signalent l'importance et l'urgence du sujet pour la direction ecclésiastique ${ }^{83}$. Il s'agit aussi du Synode restreint, instance permanente gouvernant l'Église, largement mobilisée sur la question dès 1985-1986. Enfin, à partir de mars 1986, se constitue une commission "de lutte " coordonnée par quatre évêques : les métropolites de Trikkis, Mgr Alexios, d'Alexandroupolis, Mgr Anthimos, de Thèbes, Mgr Ieronymos, de Dimitrias, Mgr Christodoulos. Ce comité de spécialistes joue un rôle actif, au printemps et durant l'été 1987, en termes de mobilisation, de coordination et de négociation avec les pouvoirs publics ${ }^{84}$. Dans ces réseaux, l'archevêque d'Athènes conserve un pouvoir d'impulsion et d'arbitrage. Il dirige les discussions tenues en Synode et sa voix reste prépondérante, notamment en cas d'absence de majorité claire. Surtout, alors qu'en fin août 1987, le conflit semble dans une impasse, Mgr Serapheim se place au premier plan ${ }^{85}$. La reprise du dialogue et l'élaboration d'un nouveau texte résultent de plusieurs entretiens personnels « au

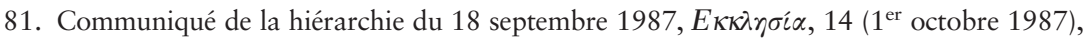

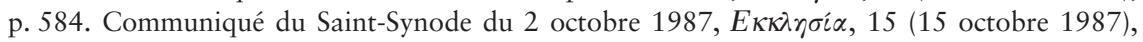

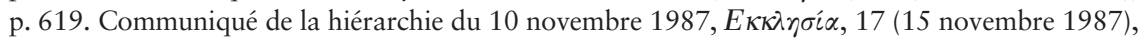
p. 686 .

82. Dans l'encyclique no 2446 de mars 1987 et dans un communiqué daté du 16 mars 1988, l'Église dénonce "une propagande débridée selon laquelle l’Église ne donnerait pas sa fortune au peuple».

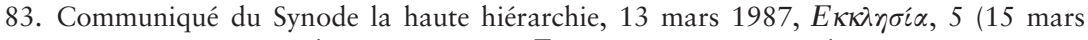

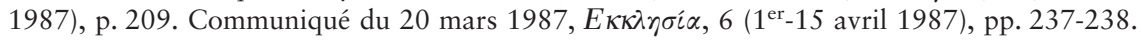

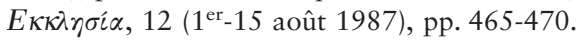

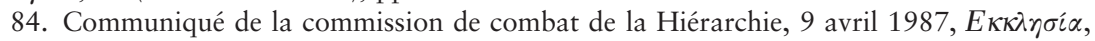
7 (1 ${ }^{\mathrm{er}}$ mai 1987$)$, p. $296 ; 7$ (1 ${ }^{\mathrm{er}}$ mai 1987), pp. 297-298. Communiqué de la commission de

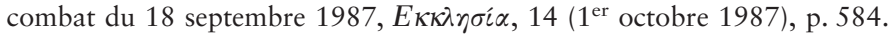

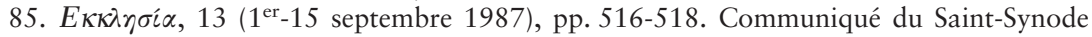

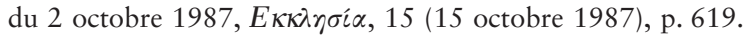


sommet ", à partir de l'été $2007^{86}$. Les autres instances ecclésiastiques sont rapidement informées et appelées à sanctionner les acquis de ces rencontres ${ }^{87}$. Néanmoins, à partir de septembre 1987, ces structures collégiales semblent perdre de leur pouvoir d'initiative au profit de l'Archevêché d'Athènes ${ }^{88}$.

Ce projet de loi a cristallisé des clivages entre Grecs de culture orthodoxe : en mars 1987, par exemple, si le journal conservateur A ко́ dénonce une agressive "soviétisation de la fortune ecclésiastique " ${ }^{89}$, pour le

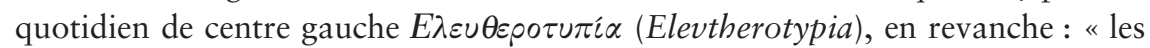
Hiérarques sont passés à la contre-offensive pour empêcher tout contrôle de la gestion de la fortune ecclésiastique (...) Le chef de la Nea Dimokratia K. Mitsotakis a offert son appui à la boulimie des évêques " ${ }^{90}$.

Si la loi 1700-1987 concerne l'Église orthodoxe de Grèce dans son ensemble, elle touche plus spécialement les biens fonciers monastiques. Un écho des divergences entre, d'une part, la haute hiérarchie épiscopale, d'autre part, certains milieux monastiques ou des franges fondamentalistes de l'Église, est perceptible dans le communiqué du Synode Permanent du 15 mars 1988. Cette instance dénonce les « ingérences des moines agiorites dans les affaires internes de l'Église orthodoxe de Grèce ». Une circulaire synodale invite, par ailleurs, les évêques à la plus grande prudence à l'égard des "provocations des moines agiorites, de manière à ne pas enflammer plus encore la question ecclésiastique ${ }^{91}$. Ces possibles crispations internes risquaient-elles d'être réactivées par la proposition gouvernementale d'introduire des membres élus dans les conseils ecclésiastiques ; d'accepter des avocats ainsi qu'une publicité accrue dans les tribunaux ecclésiastiques $^{92}$ ? Le Saint-Synode a récusé une telle «innovation », contraire aux canons

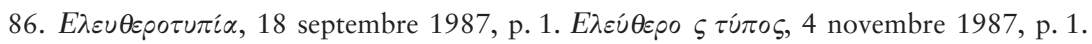

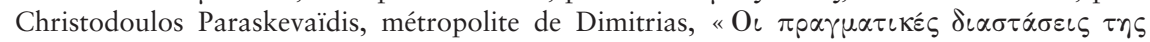

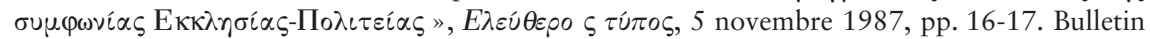

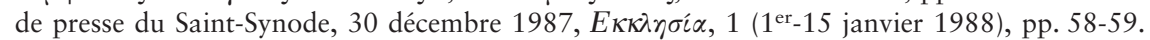

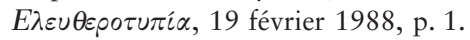

87. Bulletins de presse du 29 février et du $1^{\mathrm{er}}$ mars $1988, E \kappa \kappa \lambda \eta \sigma i \alpha, 4$ (1 ${ }^{\mathrm{er}}$ mars 1988$)$, p. 172.

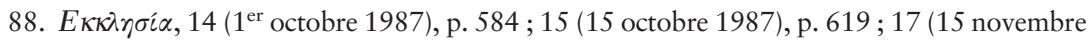
1987), pp. 686-687.

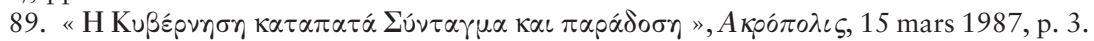

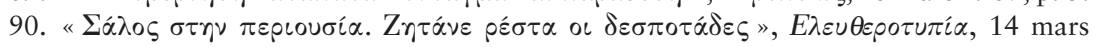
1987, pp. 1-5.

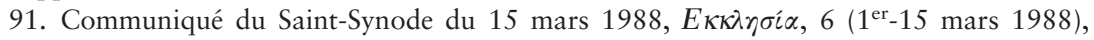
pp. 251-252. Bureau de presse du Saint-Synode, Bulletin $\Pi_{\rho} \circ \varsigma \tau o \lambda \alpha \sigma^{\circ} \mathrm{n}^{\circ} 15, H \alpha \lambda \dot{\eta} \theta \varepsilon \iota \alpha \gamma \iota \alpha \tau \eta \nu$

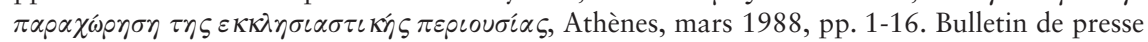

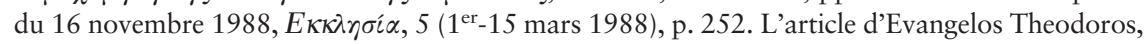

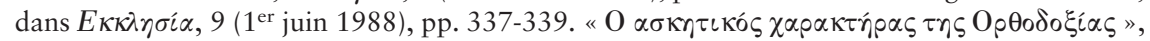

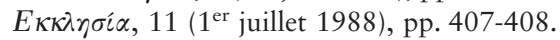

92. L'article 9 de la loi 1700-1987 - fruit d'un amendement déposé lors de la discussion parlementaire - vise à réduire l'opacité des tribunaux ecclésiastiques, dominés par la figure du métropolite, en autorisant des clercs orthodoxes, prêtres et moines, à assister aux séances. 
sacrés, accusant le gouvernement de vouloir créer artificiellement des " conflits de classe entre les évêques et les popes ${ }^{93}$. Indice, peut-être, d'un malaise,

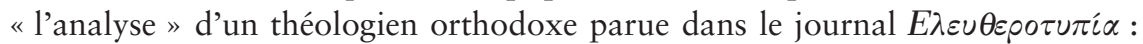
selon l'auteur, "l'administration de l'Église », refuserait " toute participation du peuple dans la gestion de la fortune ecclésiastique » tandis que le bas clergé, serait, sous la menace des tribunaux ecclésiastiques, la "proie " d'un système épiscopal « arbitraire et despotique ${ }^{94}$.

\section{Conclusion}

Dans les textes de l'Église orthodoxe, la restauration des icônes, en 787 puis en 843 , apparaît comme un processus naturel, nécessaire et souhaité. Et pourtant, en 787, la réunion du Concile de Nicée II a constitué une entreprise difficile. Le caractère " œcuménique » de la rencontre, tant revendiquée, se trouve, en effet, d'emblée contesté puisque, si des légats du pape sont bien présents, les Patriarches orientaux n'envoient pas de représentants officiels. En outre, contrairement aux thèses iconoclastes, les positions iconophiles ${ }^{95}$ peuvent moins aisément s'appuyer sur le texte des Saintes Écritures ${ }^{96}$. Le Patriarche de Constantinople, Taraise, maître d'œuvre de ce Concile, semble avoir cherché à compenser ces faiblesses en introduisant d'abord, et de manière inédite, cent trente deux moines dans l'Assemblée, contrepoids possible aux évêques (Ostrogorski, 1996 : 207 ; Auzépy, 1999 : 84) ; ensuite, en recourant, à défaut de la Bible, à la littérature hagiographique et à des coutumes non écrites (Auzépy, 1999: 85-86) ${ }^{97}$. Il s'agit, alors, d'étayer la légitimité de pratiques à caractère diffus et reconnues « depuis longtemps ». Les pères du Concile de Nicée II ont ainsi considéré le culte des icônes comme un élément constitutif de la «tradition de l'Église » et l'ont défendu en tant que tradition. Néanmoins, lors de la querelle iconoclaste, les deux camps en présence se posent comme défenseurs du christianisme et de l'orthodoxie (Parry, 1996 : 156-165) : le conflit s'est cristallisé autour de différents aspects ou lectures de la tradition ${ }^{98}$.

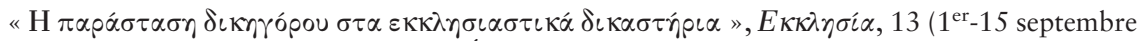
1987), pp. 544-549. Saint-Synode de l'Église de Grèce, $A \pi \delta ́ \pi \varepsilon \iota \rho \alpha \alpha \iota \chi \mu \alpha \lambda \omega \sigma i \alpha \varsigma$..., op. cit., 1987, pp. 69-70.

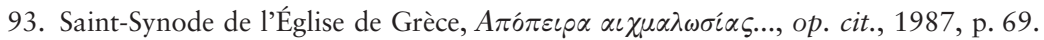

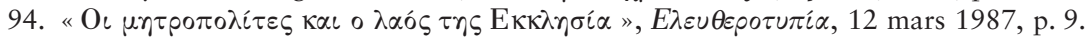

95. Dans ce contexte, le camp iconodule (littéralement " serviteurs des images »), ou iconophile, désigne les partisans du culte des images du Christ, de la Vierge et des saints.

96. L'Église des premiers siècles chrétiens se serait montrée plutôt réticente à l'égard des représentations figurées des personnages sacrés. Louis Bréhier, La Querelle des images, Bloud, Paris, 1904 ; Gouillard Jean, «Iconoclasme ", Encyclopédia Universalis, 2001.

97. Gilbert Dagron, chap. 2, in Dagron G., Vauchez A., Riché P., (dir.), L’histoire du christianisme, t. IV, Paris, Desclée de Brouwer, 1993, pp. 93-116. Sessions du concile de Nicée II, in Jean-Paul Migne, Encyclopédie théologique, Paris, 1847, vol. 13 et 14.

98. Mgr Serapheim, archevêque d'Athènes de 1974 à 1998, insiste sur le caractère dynamique de la "tradition helléno-orthodoxe ". Message de l'archevêque d'Athènes et de toute la Grèce, Mgr Serapheim, à la jeunesse, à l'occasion de la fête des trois hiérarques, $E \kappa \kappa \lambda \eta \sigma i \alpha$, 2 ( $1^{\text {er }}$ février 1995), p. 103. 
Dans son enquête ethnographique consacrée à la Grèce contemporaine - et en particulier, aux îles cycladiques - Katerina Seraïdari rappelle que, pour les croyants, les « icônes puisent dans le passé pour parler du présent » (2005: 228). Elle insiste, au fil de son étude, sur la construction, par les fidèles, de la sacralité de cet objet matériel. Ces analyses semblent tout particulièrement s'appliquer à la crise de 1987 entre l'Église et le pouvoir politique. Les manifestations autour de l'icône Axion Esti signalent, en effet, l'autonomie entre, d'une part, les intentions, les projets de la direction ecclésiastique, et d'autre part, celles, elles-mêmes polysémiques, des fidèles. Pour ces derniers, les relations à l'icône renvoient étroitement à un vécu personnel. Pour la haute hiérarchie orthodoxe, comme pour les représentants de l'État, ces démonstrations viennent cristalliser, par leur force symbolique, une logique de réconciliation. La crise grecque de 1987-1988 met en relief le cas où le haut clergé impulse et encourage, voire cherche à canaliser, la piété populaire dans le cadre d'une entreprise de mobilisation, de résistance et, enfin, d'apaisement. En 1987, la direction ecclésiastique refuse de céder des terres monastiques à des coopératives "politisées ». Mais ne souligne-t-elle pas les dons fonciers constants de l'Église à la nation ? N'expose-t-elle pas, par ailleurs, en novembre 1987, un "trésor » du Mont Athos, rapprochant, ainsi, les Athéniens d'une icône estimée miraculeuse?

Cette étude permet d'aborder une question à la fois sensible et largement opaque en Grèce - celle du patrimoine ecclésiastique - thème qui revient, à la fin 2008, au premier plan de l'actualité ${ }^{99}$. Elle vient confirmer trois points sur lesquels il convient d'insister. L'héritage impérial chrétien oriental demeure, pour l'Église orthodoxe de Grèce, une ressource d'une grande richesse. La tradition - principe majeur de fonctionnement et de légitimation pour l'institution religieuse - représente un corpus susceptible d'être constamment re-sémantisé. Enfin, au seuil du XXI siècle, en Grèce, des symboles religieux peuvent, combinés à d'autres modes d'action, participer d'une stratégie de mobilisation au final efficace.

Isabelle DÉPRET

CIERL - Université Libre de Bruxelles isdepret@gmail.com

99. À l'automne 2008, plusieurs députés du PASOK révèlent des transactions foncières jugées désavantageuses pour l'État grec entre des membres du gouvernement et certains segments de l'administration, et le monastère athonite de Vatopedi : voir Nikos Alivizatos, "To

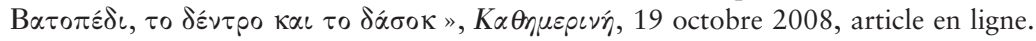




\section{Bibliographie}

ARHWeILER Hélène, 1975, L'idéologie politique de l'Empire byzantin, Paris, Presses Universitaires de France.

AnASTASSIADIS Tassos, 2007, «Dieu vomit les tièdes! Modernisation ecclésiastique et intolérance religieuse. Contribution sur la considération des relations État-Église en Grèce dans l'entre-deux-guerres ", in Grivaud G., Petmezas S., (dirs.), ByzantinaModerna. Mélanges en l'honneur d'Hélène Antoniadis-Bibicou, Athènes, Alexandreia, pp. 449-466.

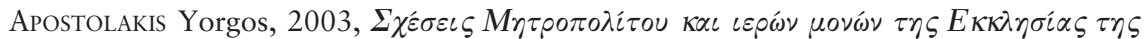
$E \lambda \lambda \dot{\alpha} \delta \circ \varsigma$ [Relations entre le métropolite et les saints monastères de l'Église orthodoxe], Trikala, Protypes Thessalikes Ekdoseis.

AuZEPY Marie-France, 1999, Hagiographie et iconoclasme. Le cas de la Vie d'Étienne le Jeune, Aldershot, Ashgate-Variorum Reprints.

-, 2006, L'iconoclasme, Paris, Presses Universitaires de France.

Albert-Llorca Marlène, 2002, Les Vierges miraculeuses. Légendes et rituels, Paris, Gallimard.

Badone Ellen, (dir.), 1990, Religious Orthodoxy and Popular Religion in European Society, Princeton, Princeton University Press.

BaLta Evangelia, 1995, Les vakifs de Serrès et de sa région (XV ${ }^{e}-\mathrm{XVI}^{e}$ siècles), Athènes, KNE-EIE.

Brown Peter, 1981, The Cult of Saints. Its Rise and Function in Latin Christianity, Berkeley, University of California Press.

Chatzisavas Andreas, 2004, "Fêtes religieuses et pratiques païennes : les dodécamera, fêtes dites de douze jours dans différentes régions de Grèce », in Alexandre P., (dir.), Religions, nations, identités, Nancy, Presses Universitaires de Nancy, pp. 119-123.

Dagron Gilbert, MaYeur Jean-Marie, Vauchez André, (dirs.), 1995, Histoire du christianisme, t. V. Apogée de la papauté et expansion de la chrétienté 1054-1272, Paris, Desclée de Brouwer.

Dagron Gilbert, 1996, Empereur et prêtre. Étude sur le "césaropapisme " byzantin, Paris, Gallimard.

Deguilhem Randi, 2003, "Le wakf dans l'Empire ottoman jusqu'en 1914 », Encyclopédie de l'Islam, XI, pp. 95-101.

DÉPRET Isabelle, (à paraître), Église, État, nation en Grèce contemporaine. Lectures historiques, sécularisation, mobilisation, Paris, Athènes, Publications de l'École française d'Athènes.

DubISCH Jill, 1991, "Gender, Kinship and Religion. Reconstructing the Anthropology in Greece ", in Loïzos P., Papataxiarchis E., (dirs.), Contested Identities. Gender and Kinship in Modern Greece, Princeton, Princeton University Press, pp. 29-47.

FrazeE Charles, 1969, The Orthodox Church and Independent Greece, 1821-1852, Cambridge, Cambridge University Press.

Geanakoplos Georges, 1965, "Church and State in the Byzantine Empire. A Reconsideration of the Problem of Caesaropapism ", Church History, 34, pp. 381-403.

Gialakis Ambrosios, 2005, Images of the Divine. The Theology in the VII ${ }^{\text {th }}$ Ecumenical Council, Leiden, Brill.

Gouillard Jean, 1967, "Traduction du Synodikon de l'orthodoxie (843) », in Travaux et Mémoires 2, Paris, Éditions de Boccard. 
HatzFeld Henri, 1993, Les racines de la religion. Tradition, rituel, valeurs, Paris, Éditions du Seuil.

Hervieu-Léger Danièle, 1999, "Tradition-Traditionalisme ", in Dictionnaire de sociologie, Paris, Robert-Éditions du Seuil, 1999.

HerzFeld Michaël, 1990, "Icons and Identity: Religious Orthodoxy and Social Practice in Rural Crete ", Anthropological Quaterly, 63-3, pp. 109-112.

Hobsbawm Eric, Ranger Terence, (dirs.), 1993, The Invention of Tradition, Cambridge, Cambridge University Press.

Hussey Joan, The Orthodox Church in the Byzantine Empire, Oxford, Clarendon Press, 1986, pp. 299-301.

Kaplan Michel, 2007, Byzance, Paris, Les Belles-Lettres.

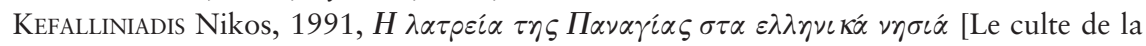
Vierge dans les îles grecques], Athènes, Philippotis.

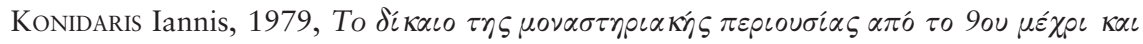

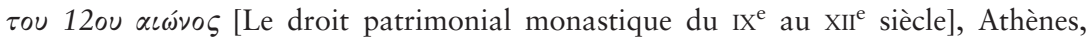
Sakkoulas.

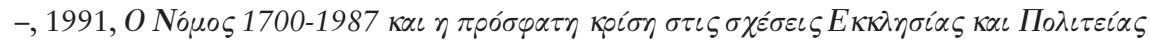
[La loi 1700-1987 et la récente crise dans les relations entre l'Église et l'État], Athènes, Sakkoula.

-, 1991, "Les monastères dans l'Église orthodoxe de Grèce ", Archives des Sciences Sociales des Religions, 75, pp. 11-22.

Lemerle Paul, 1975, Histoire de Byzance, Paris, Presses Universitaires de France.

MAKRIDES Vassilios, 2004, «L'autre orthodoxie : courants du rigorisme orthodoxe grec », Social Compass, 51-4, pp. 511-521.

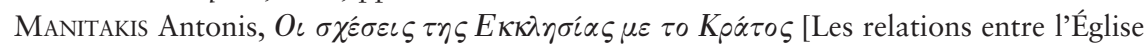
et l'État], Athènes, Nefeli, 2000.

MeErson Michael, "The Doctrinal Foundation of Orthodoxy ", in Ramet P., (dir.), Eastern Orthodoxy and Politics in the $\mathrm{XX}^{\text {th }}$ Century, Durham, Duke University Press, 1988, pp. 20-22.

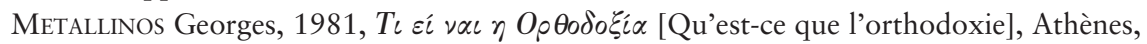
Apostoloki Diakonia.

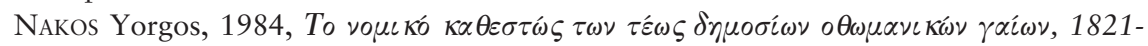
1912 [Le régime juridique des anciennes terres publiques ottomanes 1821-1912], Salonique, University Studia Press.

Odorico Paolo, (dir.), 1996, Conseils et mémoires de Synadynos, prêtre de Serres en Macédoine (XVII ${ }^{e}$ siècle), Paris, Éditions de l'Association Pierre Belon.

Ostrogorski Georgije, 1996, Histoire de l'Empire byzantin, Paris, Payot.

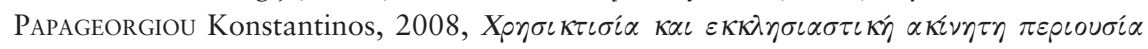
[Usucapion et fortune immobilière ecclésiastique], Trikala, Protypes Thessalikes Ekdoseis.

PAPASTATHIS Charalambos, 1999, «La République hellénique », in Basdevant-Gaudemet B., Messner P., (dirs.), Les origines du statut des confessions religieuses dans les pays de l'Union européenne, Paris, Presses Universitaires de France, pp. 207-221.

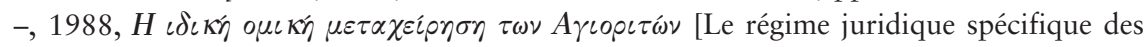
moines du mont Athos], Athènes, Kyriakidis.

Papathomas Grigorios, 1998, Le Patriarcat œecuménique de Constantinople y compris la Politeia monastique du Mont Athos dans l'Europe unie. Approche nomocanonique, Katerini, Ekektasi. 
PARRY Kenneth, 1996, Depicting the Word. Byzantine Iconophile Thought in the vIII th $^{\text {th }}$ and the IX ${ }^{\text {th }}$ Centuries, Leiden, Brill.

Pentcheva Bissera, 2006, Icons and Power. The Mother of God in Byzantium, University Park, Pennsylvania University Press.

Prodromou Elizabeth, 1998, "Democratization and Religious Transformation in Greece. An Underappreciated Theoretical and Empirical Premier ", in Veremis T., Kitromilidis P., (dirs.), The Orthodox Church in a Changing World, Athens, Centre for Asia Minor Studies, pp. 99-153.

SÉGUY Jean, 1977, "Images et religion populaire. Réflexion sur un colloque ", Archives de sciences sociales des religions, 44-1, pp. 25-43.

SÉRAÏDARI Katerina, 2005, Le culte des icônes en Grèce, Toulouse, Presses Universitaires du Mirail.

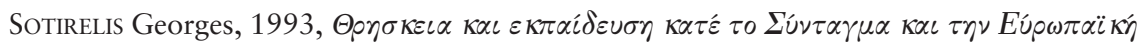
$\Sigma u ́ \mu \beta \alpha \sigma \eta$ [Religion et éducation selon la Constitution et la Convention européenne], Athènes-Komotini, Sakkoulas.

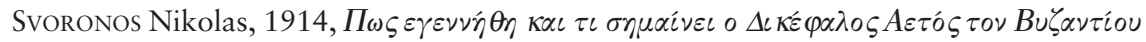
[Comment est né et que signifie l'aigle bicéphale de Byzance], Athènes, Nea Estia.

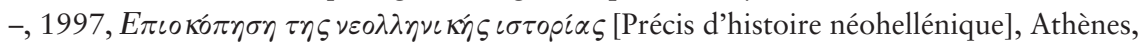
Themelio.

Tradigo Alfredo, 2006, Icons and Saints of the Eastern Orthodox Church, Los Angeles, JP Getty Museum.

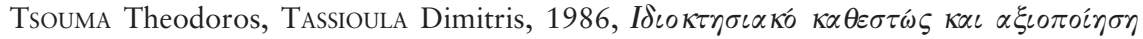

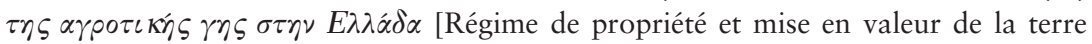
agricole en Grèce], Athènes, ATE.

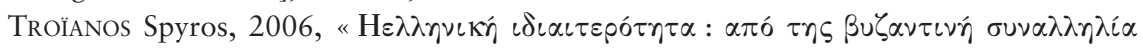

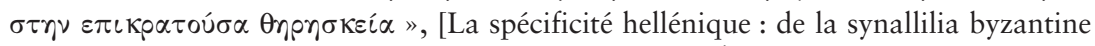
à la religion dominante], Intervention à l'Académie des Études théologiques, Athènes, $1^{\text {er }}$ avril 2006.

Valtchinova Galia, 2002, "Orthodoxie et communisme dans les Balkans. Réflexions sur le cas bulgare ", Archives de Sciences sociales des Religions, 119, pp. 77-99.

Vauchez André, Mayeur Jean-Marie, (dirs.), 1993, Histoire du christianisme, t. IV. Evêques, moines et empereurs, 612-1054, Paris, Desclée de Brouwer.

Velmans Tania (dir.), 2005, Icônes. Le monde orthodoxe après Byzance, Milan, Jaca Books-Hazan.

Ware Thimothy, 1997, The Orthodox Church, London, Penguin. 


\section{Résumé}

L'examen d'une crise survenue, en Grèce, entre pouvoirs ecclésiastique et temporel est l'occasion de revenir sur la notion de tradition et sur la place des icônes dans l'Église orthodoxe. Nous nous appuyons sur des documents juridiques, sur la presse ecclésiastique, ainsi que sur la presse généraliste hellénique. Ces sources permettent de saisir les controverses cristallisées, en 1987-1988, autour d'une loi relative an patrimoine ecclésiastique. Sont mis en relief l'insertion et l'usage - dans ce contexte polémique - de références, images et pratiques religieuses. Cette étude de cas suggère que, dans la Grèce de la fin du XXe siècle, des symboles religieux-combinés à d'autres modes d'action - peuvent participer d'un effort de mobilisation, de résistance et de cohésion au final assez efficace.

Mots-clés: Grèce, Église orthodoxe, patrimoine ecclésiastique, symboles religieux.

\section{Abstract}

The examination of a crisis between the higher clergy and the Greek Government offers the opportunity to reconsider the issue of tradition and the significance of icons in the Orthodox Church. We refer to legal documents, to ecclesiastical publications and to the Greek press. Through these sources, we focus on a controversial law regarding ecclesiastical property, in 1987-1988. We emphazise the integration-in a contentious context-of references, images and religious practices. This case study shows that in the end of $X^{\text {th }}$ Century's Greece, the use of religioux symbols-combined with other methods-can contribute to a rather effective rallying and resistance strategy.

Key words: Greece, Orthodox Church, ecclesiastical patrimony, religious symbols.

\section{Resumen}

El examen de una crisis acaecida en Grecia entre los poderes eclesiástico y temporal nos brinda la ocasión de volver sobre la noción de tradición y sobre el lugar de los iconos en la Iglesia ortodoxa. Trabajaremos en este artículo con documentos jurídicos, con la prensa eclesiástica y con la prensa helénica en general. Estas fuentes permiten abordar las controversias cristalizadas, en 1987 y 1988, alrededor de una ley relativa al patrimonio eclesiástico. Son puestas en relieve la inserción y el uso -en este contexto polémico- de referencias, imágenes y prácticas religiosas. Este estudio de caso sugiere que, en la Grecia de fin del siglo XX, los simbolos religiosos - combinados con otros modos de acción- pueden participar de un esfuerzo de movilización, de resistencia y de cohesión que resulta finalmente bastante eficaz.

Palabras clave: Grecia, Iglesia ortodoxa, patrimonio eclesiástico, símbolos religiosos. 